\title{
Retention of Knowledge: A Comparative Analysis in Petrol Engine Using Interactive Computer Simulation and Computer Simulation Video
}

\author{
${ }^{1}$ IGWE,N., ${ }^{2}$ EKEAGWU,A. U. and ${ }^{3}$ ONELE, N.O. \\ ${ }^{1}$ Department of Industrial Technical Education, University of Nigeria, Nsukka \\ ${ }^{2}$ Federal Government Girls' College Lejja Nsukka \\ ${ }^{3}$ Technology and Vocational Education, Ebonyi State University Abakaliki
}

\begin{abstract}
This study compared two groups of four technical college classes studying automobile engine. One group learned using interactive computer simulation; the other group learned using computer simulation video. The study adopted a posttest, retention test, control group, quasi-experimental research design. There were three weeks (of 45 minutes each) of treatment for the study. Cognitive achievement and psychomotor performance tests were used to obtain data. The area of the study is Enugu State of Nigeria. 526 NTC 1 (average of 16-17 years old) students of Motor Vehicle Mechanics' Work formed the population of the study; while 120 students were sampled from 4 schools out of the 22 schools managed by Science Technical and Vocational Schools Management Board (STVSMB), Enugu. The correlation coefficient of stability of the cognitive achievement test was 0.82. Arithmetic mean was utilised to answer the research question, while the hypothesis was tested, at .05 level of significance, using Analysis of Covariance (ANCOVA). The study found that the group taught using computer simulation video performed better than those using interactive computer simulation. It was also found that the difference was not significant. Based on the findings, one of the recommendations made is that computer simulation video teaching technique should be incorporated in the teaching of Motor Vehicle Mechanics' Work.
\end{abstract}

\section{Introduction}

The recent National Technical Certificate Examination results in Motor Vehicle Mechanics' Work in Enugu State depict only 4\% distinction pass. The National Technical Certificate Examination assesses on the knowledge the students have retained during their stay in technical colleges. Aina (2008) and Ibrahim \& Abdullahi (2014) identified teaching methods as one of the major causes of academic failure in National Business and Technical Examinations. Teachers in Enugu State technical colleges conventionally use static picture multimedia in teaching. Mayer (2011) refers multimedia instruction as learning environments that contain both words and pictures with the intention to promote learning. The words may be printed (as in a magazine article) or spoken (as in a narration); and the pictures may be static (such as diagrams, illustrations, or photos in PowerPoint slides) or dynamic/motion (such as an animation or video in an online lesson or computer simulation). The promise of multimedia instruction is that people can learn better from words and pictures than from words alone (Mayer, 2009).

Computer simulation is a dynamic multimedia that mimics real life. Researchers have found it better than using static multimedia, mostly due to its facility in relearning. Envisaging the importance of using dynamic multimedia in teaching and learning in Motor Vehicle Mechanics' Work, Federal Government of Nigeria (NBTE, 2009) recommended that there should be a sub-section of Diagnosis/Computer/Simulator in automobile section. This section is where simulators, such as computer simulations, should be used to instruct Motor Vehicle Mechanics' Work students in Nigeria. Computer simulation makes it possible for the student to visualise the dynamic processes in a running engine. Presently, there is no school in Enugu State technical colleges that has sub-section of Diagnosis/Computer/Simulator in automobile section.

There is therefore the need to carry out a study on different types of computer simulation to ascertain a more effective one that could be used in Enugu State technical colleges, more so in Motor Vehicle Mechanics' Work. Mayer, Heiser \& Lonn (2001) posit that although adding pictures to words can improve learning, not all graphics are equally effective and some are even detrimental. The challenge of multimedia instruction is to figure out how to design effective lessons using words and pictures. There are different kinds of computer simulations used to teach students in all fields. This study sought to find out the lesson presentation between interactive computer simulation and computer simulation video that has a better effect on the academic achievement of the technical college students in Motor Vehicle Mechanics' Work.

Interactive computer simulation software enables users (teachers and students) make decisions and input these decisions into the computer. The computer uses the model to calculate new values for the new inputs 
in the system. Rigby (2015) defines interactive computer simulation as a program that embodies some model or an aspect of the world, allows the user to make inputs to the model, runs the model, and displays the results. A computer simulation video, on the other hand, describes a diverse super-category of video, generally designed to closely simulate aspects of a real or fictional phenomenon (Rollings \& Ernest, 2003).

The difference between interactive computer simulation and computer simulation video is in the interaction. Unlike the interactive computer simulation, the computer simulation video cannot 'interact' with the student. Interaction here means that the student can input different values in order to experience the output of those different values of what could be in real life situation. The only input that could be made in computer simulation video is speed reduction and increment or pause, on the processes of interest.

\section{Methods}

In this study, a quasi-experimental research design of post test and retention test, experimental-controlgroup model was used. This study was carried out on 120 NTC 1 students in second term of 2015/2016 academic session. The study involved two groups of subjects. They control themselves. One group were taught using interactive computer simulation teaching technique and the other group were taught using computer simulation video teaching technique. Only the scores of students who participated in post test and retention were taken to analyse the data; therefore the interactive computer simulation (ICS) group consists of 51 students and that of the computer simulation video (CSV) group were 47 students. The study was conducted in Enugu State, Nigeria. Cognitive achievement and psychomotor performance tests were used to obtain scores from students. The study was conducted during the school lesson period. It followed the classes' time table of Motor Vehicle Mechanics' Work. The regular school Motor Vehicle Mechanics' Work teachers were used in the study. Posttest was administered to both groups. After three weeks, retention test was also administered to the two groups. The data collected from the posttest and retention test were used for further analysis. The analysis determined if there are significant differences in the cognitive achievement and psychomotor performance between the two groups.

Results: The results are presented according to the research question and hypothesis that guided the study.

\section{Research Question}

What are the mean retention performance scores of students of Motor Vehicle Mechanics' Work taught using interactive computer simulation teaching technique and students taught using computer simulation video teaching technique?

The answer to this research question is provided in table 1.

Table 1 Mean Scores of Post and Retention tests of Students of MVMW taught using Interactive Computer Simulation Teaching Techniques and those taught using Computer Simulation Video Teaching Technique

\begin{tabular}{|c|c|cc|c|c|}
\hline Techniques & N & Post-test & \multicolumn{2}{|c|}{ Retention Test } & \multirow{2}{*}{ Mean Gain } \\
\cline { 3 - 5 } & & $X$ & $X$ & \\
\hline ICS & 51 & 44.18 & 46.54 & 2.36 & \\
CSV & 47 & 44.20 & 49.25 & 5.05 & \\
\hline
\end{tabular}

Table 1 show that students taught MVMW using ICS technique had a mean score of 44.18 in the posttest and a mean score of 46.54 in the retention test; making a post test, retention test mean gain in the students taught using ICS technique to be 2.36. Meanwhile, students taught MVMW using CSV technique had a mean score of 44.20 in the post test and a retention test mean of 49.25 with a post test, retention test mean gain of 5.05. With these results, students taught MVMW using CSV technique had mean scores greater than students using ICS technique in retention test; thus, there is a higher effect attributable to teaching technique on the retention test of students taught MVMW using CSV technique than those taught using ICS.

\section{Null Hypothesis:}

There is no significant difference between the mean retention scores of students taught using interactive computer simulation teaching technique and those taught using computer simulation video teaching technique. The data analysed for this hypothesis is presented in Table 2.

Table 2 Summary of Analysis of Covariance (ANCOVA) for Test of Significance between the Mean Scores of ICS and CSV in the Retention Performance Test

\begin{tabular}{|l|l|l|l|l|l|}
\hline Source & Type III Sum of Squares & Df & Mean Square & F & Sig. \\
\hline Corrected Model & $3134.083^{\mathrm{a}}$ & 3 & 1044.694 & 24.938 & .000 \\
\hline Intercept & 153131.871 & 1 & 153131.871 & $3.655 \mathrm{E} 3$ & .000 \\
\hline Group & 26.512 & 1 & 26.512 & $.633^{*}$ & .429 \\
\hline Location & 2652.487 & 1 & 2652.487 & $63.317 *$ & .000 \\
\hline Group * Location & 320.688 & 1 & 320.688 & 7.655 & .007 \\
\hline
\end{tabular}


Retention Of Knowledge: A Comparative Analysis In Petrol Engine Using Interactive Computer...

\begin{tabular}{|l|l|l|l|l|l|}
\hline Error & 2932.463 & 70 & 41.892 & & \\
\hline Total & 173952.293 & 74 & & & \\
\hline Corrected Total & 6066.546 & 73 & & & \\
\hline *significant at sig of $\mathbf{F}<\mathbf{. 0 5}$ & & & & \\
\hline
\end{tabular}

The data presented in Table 2 shows that $F$ calculated value for group is .633 with significance of $F$ at .429 which is greater than 0.05 . Therefore, the null hypothesis of no significant difference between the effect of interactive computer simulation teaching technique and computer simulation video teaching technique in the retention performance in MVMW is accepted at 0.05 level of significance. Hence, there was no significant difference between students taught using interactive computer simulation teaching technique and those taught using computer simulation video teaching technique, in respect to their mean scores on the MVMW Retention Performance Test.

\section{Discussion}

The data presented in Table 1 provided answer to the research question. Findings revealed that the computer simulation video teaching technique is more effective in improving students' retention performance in Motor Vehicle Mechanics' Work than the interactive computer simulation teaching technique. This is similar to the findings of Bhat, Twigg, Hodgins, Khosla, Popovi and Seitz (2003); who in their studies found out that the implementation of computer simulation video in the teaching of clothing; students had an improved psychomotor performance in the course than the students taught using interactive computer simulation.

A possible explanation for the effectiveness of the computer simulation video teaching technique is the level of NTC1 students of Motor Vehicle Mechanics' Work. Pekdağ (2010) opined that educational tools should be designed to serve pedagogical purposes. Designs must consider both a student's prior knowledge and the development of knowledge over the course of the student's learning process. Moreover, the design of technological tools should consider the advantages that will be made available to curriculum as well as respond to the needs of students. That is, if a teacher is to benefit from a technological tool (animation, simulation or video) in the transfer of knowledge, the information provided by means of that technological tool must be appropriate to the student's level of knowledge. Another matter to be considered in the design of technological tools is cognitive load. The concept of cognitive load is defined as the mental cost of what is necessary to achieve activity in an individual's cognitive system. Technological tools should be designed so as not to create an extreme load for the student's cognitive system. Computer simulation video, used in this study, considered the above criteria more than the interactive computer simulation (also used in this study). Interactive computer simulation, as used in this study, may be intellectually higher than the NTC 1 students in terms of retention performance demonstration.

Furthermore, the processes involved in the assembling and disassembling of Float Type Carburettor System, as used in this study, are depicted clearer in Computer Simulation Video than in Interactive Computer Simulation. Yuen (2012) stated that Video as a rich medium have been known to be advantages in engaging learners, capturing and demonstrating content which are difficult to articulate with text or image alone as well as functioning as a medium for reflection. Videos are used as a motivational tool and as a medium to grab students' attention. Video is a popular and engaging medium especially to students with short attention span, such as most NTC 1 students (considering their age and exposure in automobile technology); as it is a rich medium presenting materials that incorporates multimedia content for e-learning. Interactive videos, such as the one used in this study, allow students to have repetitive viewing where they can pause and replay the content to help understanding and improve retention.

In addition, Martínez, Pérez, Suero \& Pardo (2012) advised that instructional videos constitute a virtual guide to the experiments which student carries out. This is an advantage when there is little workshop equipment available. Approaching workshop practices sequentially in an instructional video can optimize both the available material resources and the available time. Video can facilitate the students' preparation prior to their actually doing the workshop practices by describing the basic theoretical concepts related to the experiment they are going to see. This virtual laboratory does not mean that real workshops should be phased out. Instead that should be an integration of the two laboratories in teaching practice. Indeed, it forms part of a teaching methodology which foresees increasing use of a wide range of learning tools. The purpose of using computer simulation teaching technique is their application to e-learning platforms as complements to traditional teaching, and not as replacements for real workshops where such workshops are available. Nonetheless, when a real laboratory is unavailable or inaccessible, computer simulation video can of course be very useful indeed. Computer simulation video ideal use is as a teaching resource that can be used for pre-practical and postpractical study, allowing the acquisition of knowledge to be more efficient.

Analysis of covariance explained the null hypothesis in Table 2. It revealed that at calculated F-value of .633, significant of $\mathrm{F}$ at .429 and confidence level of 0.05 there was no statistically significant difference in the mean gain effect of interactive computer simulation teaching technique and computer simulation video teaching technique, on students' retention performance in Motor Vehicle Mechanics' Work; confirming that the 
difference between the mean gain effect of interactive computer simulation teaching technique and computer simulation video teaching technique can be attributed to chance. Hence, the null hypothesis of no significant difference between the effects of treatment on students' retention performance in MVMW was upheld at 0.05 level of significance.

\section{Conclusion}

Based on the analysis of data, it is concluded that computer simulation video teaching technique is better than interactive computer simulation teaching technique in retention performance. The study also revealed no significant difference in retention performance between the two teaching techniques. These results therefore showed that computer simulation video teaching technique is viable alternative to the conventional teaching method in retention performance for Motor Vehicle Mechanics' Work.

\section{Recommendations}

Based on the findings of this study, the following recommendations are made:

1. National Board for Technical Education (NBTE) should consider review of curriculum for Motor Vehicle Mechanics' Work with a view to incorporating computer simulation video teaching technique into the teaching of Motor Vehicle Mechanics' Work.

2. In order to promote retention performance in Motor Vehicle Mechanics' Work, their teachers and school administrators should incorporate the use of computer simulation video teaching technique in their teaching Motor Vehicle Mechanics' Work.

3. Workshops, seminars and conferences and in-service training should be organized by the government and professional bodies like the National Board for Technical Education (NBTE) and the Nigerian Association of Teachers of Technology (NATT) on the use of computer simulation video teaching technique for improving students' performance in Motor Vehicle Mechanics' Work.

4. Teachers training tertiary institutions, where Information and communication Technology (ICT) has not been introduced, should include ICT in their curricula and impact the use of computer simulation video instruction strategy to the student teachers.

\section{Reference}

[1]. Aina, O. (2008). Report study panel on technical teachers production in Nigeria (1) Lagos: Federal Ministry of Education Retrieved from http://www.iosrjournals.org/iosr-jmce/papers/vol1-issue4/B0140713.pdf on January 14, 2013

[2]. Bhat, K. S., Twigg, C. D., Hodgins, J. K., Khosla, P. K., Popovi Z. \& Seitz, S.M. (2003). Estimating cloth simulation parameters from video. Retrieve from http://repository.cmu.edu/cgi/viewcontent.cgi?article=1514\&context=isr

[3]. Ibrahim, Y. U., \& Abdullahi, S. M. (2014). Repositioning the facilities in technical college workshops for efficiency: A case study of North Central Nigeria. Retrieved from http://scholar.lib.vt.edu/ejournals/JSTE/v47n3/umar.html on January 14, 2015

[4]. Martínez, G., Pérez, A. L., Suero, M. I., \& Pardo, P. J. (2012). ICTs and their applications in education. Retrieved from: http://www.intechopen.com/ books/methodologies-toolsand-new developments-for-e-learning/icts-and-their-applications-ineducation on August 16, 2015

[5]. Mayer, R. E. (2009). Multimedia learning, 2nd ed. New York: Cambridge University Press. Retrieved from http://hilt.harvard.edu/blog/principles-multimedia-learning-richard-e-mayer on August 16, 2015

[6]. Mayer, R. E. (2011). Applying the science of learning to multimedia instruction. Retrieved from http://education.ucf.edu/rtp3/docs/rtp3_mayer_article_applying_the_science_of_learning.pdf on August 16, 2015

[7]. Mayer, R. E., Heiser, H., \& Lonn, S. (2001). Cognitive constraints on multimedia learning: When presenting more material results in less understanding. Journal of Educational Psychology. 93 (187-198) DOI: 10.1037//0022-0663.93.1.187 on August 16, 2015

[8]. NBTE (2009). National technical certificate and advanced national technical certificate curriculum and module specification for vehicle mechanics' work. Kaduna: NBTE

[9]. Pekdağ B. (2010). Movies in chemistry. Pacific Forum on Science Learning and Teaching. Retrieved from https://www.ied.edu.hk/apfslt/download/v11 issue1 files/pekdag.pdf

[10]. Rigby, K. T. (2015). Real-time Computer-based Simulation as an Intervention in Aerodynamics Education. Journal of Aviation/Aerospace Education \& Research, 24(2). http://dx.doi.org/10.15394/jaaer.2015.1634 on June 24, 2015

[11]. Rollings, A. \& Ernest, A. (2003). Andrew Rollings and Ernest Adams on game design. Retrieved from http://my.safaribooksonline.com/1592730019/ ch14?portal=adobepress. on January 14, 2015

[12]. Yuen, M. (2012). User generated videos as support for teaching and learning 3D animation. Retrieved from https://kyvyt.fi/artefact/file/download.php?file=228808\&view 